\title{
MULTIPLE PERSONALITY DISORDER: A MYTH OR A REALITY? CASE REPORTS AND LITERATURE REVIEW
}

\author{
A.O. OSEI \\ Ankaful Psychiatric Hospital, P.O. Box 412, Cape Coast, Ghana.
}

\section{SUMMARY}

Multiple personality disorder, a condition in which the patient has alternating personalities manifesting in his body at different times, has been known over the ages. It was, however, considered rare until quite recently when increased attention has led to an upsurge of the diagnosis. In spite of the increase in the rate of diagnosis doubts exist as to the reality of the condition with some authors thinking it is only a production of the clinician. In Ghana the condition has previously not been reported. Two cases are reported here alongside a review of the literature to show the trend in the discussion on the diagnosis and to support the existence of the condition as a true and valid nosological entity. Both patients were females. There was no history of childhood abuse. Traumatic experience in adulthood was, however, elicited in both cases. One had four alters while the other had two. One case responded to short-term psychotherapy, anticonvulsants and antidepressants. The other defaulted before treatment could begin. It is concluded that multiple personality disorder is a genuine diagnosis which requires the consideration of clinicians.

Keywords: Multiple personality disorder, dissociative identity disorder, dissociative disorder.

\section{INTRODUCTION}

Multiple personality disorder (MPD) is a condition in which the patient shows multiple identities as if he possesses two or more selves at different times in the same body. These selves have each its own characteristic moods, memories and behavioural repertoire $^{1,2}$. This has been known since long, appearing in the literature as far back as 1800 to date ${ }^{3}$. Yet even today there is still a lot of skepticism as to whether MPD really exists as a true nosological entity ${ }^{4,5}$. Sometimes the argument as to its existence has been reduced to mere belief or disbelief $f^{6}$. In our part of the world cases of possession and trance states, just as multiple personality disorder, are not likely to report to the hospital, yet they are recognized phenomena in psychiatry ${ }^{7}$. Most of such cases in our culture would land at the prayer camps, church houses and traditional heal- ing centres even as other psychiatric conditions find themselves at these centres ${ }^{8}$. The possession of the traditional healer and the phenomenon of deliverance at the churches and the prayer camps are dissociatve states. Our environment is a highly religious and, one may say, superstitious one, and we daily confuse superstition with religion where we see a lot of things in superstitious context, thus a lot of these phenomena will fall outside the cases we see at the hospital.

In this paper we report of two cases of MPD seen at the consulting room within a week period and we use them to support the argument that MPD is a clear nosological entity in psychiatry which has to be distinguished from other cases like borderline personality disorder. The literature is also surveyed for discussion on this interesting diagnosis.

\section{CASE 1}

This was a 52-year old trained teacher Madam EA, a second wife and a mother of two, a girl and a boy. EA accompanied her husband and their 18year old daughter who was a patient we were seeing for the first time. The patient (the daughter) was reporting with severe headache and fits of six months duration. The examiner was physically examining the patient who had a high blood pressure of $190 / 130 \mathrm{mmHg}$ (for an 18 year old girl!) when EA, sitting close to the consulting table, suddenly stared blank and began to tremble in the right arm. This examiner tapped her on the shoulder and asked what was happening. The following discourse then ensued:

EA: (in an anxious tone) Please doctor, I have something to say

Examiner: Carry on

EA: "Don't worry about the girl's condition. It is not an illness for the hospital. It is a spiritual problcm. Don't you realize the 'blood has gone too high for her?' I caused it. I do not want her mother to continue marrying my father (Pointing to the patient's father sitting by)".

The examiner, at this stage figuring out what might be happening, dismissed the patient (the daughter) and urged the discourse (with EA) to 
resume demanding to know the identity of the speaker:

EA: "I am Mr. K, also a teacher, and EA is my step-mum. My mother is the elder wife and I want EA to leave the marriage. My father has been spending too much on EA and her children but my father ignores my advice. I therefore took the girl to a traditional shrine so I am the spirit of the shrine talking to you now. I have been following them wherever they go".

At this stage the examiner tried to do amytal test (drug-assisted interview) but the alter (the supposed Mr. K.) protested saying EA is not sick and does not require medication, and that when he $\mathrm{Mr}$. $\mathrm{K}$ was through he would leave EA. The examiner obliged and asked ' $\mathrm{Mr}$. $\mathrm{K}$ ' to leave. EA then suddenly stared blank again and trembled in the right arm, oblivious of the environment for a few seconds and then rubbed the face, looked around her and asked in a soft tone 'where is my daughter?' When asked what had just happened she had no memory of it. The husband confirmed that Mr. K. is his son by his first wife who is still in marriage, that the two women do not get on very well as rivals, that Mr. K. had actually suggested to the father that he divorced EA, that EA had been getting these attacks at least six times a day for six months and that they were worried about not having a solution in spite of being at various prayer healers. EA denied ever being sexually abused as a child. We recommended EA to be put on treatment by us. We, however, referred her daughter for further treatment, after laboratory investigations confirmed a diagnosis of Acute Glomerulonephritis with severe hypertension. EA has since not reported.

\section{CASE 2}

This was Miss HE, a young lady of 23 years, single and a secretary by profession. She reported with an elder sister a week after Case 1. Miss HE had been seen a month earlier by another colleague. Her complaints were that for one year three different voices at different times spoke through her. They had tried several prayer healers without' success as the voices kept coming almost every thirty minutes. She had thus not been going to work. One voice claimed to be her maternal aunt (MA), one a prospective mother-in-law (PM). and the other the girlfriend (GF) of her fiancé. GF was allegedly an Ashanti while HE is a Fanti who is not fluent in Asante-Twi, the dialect of Ashantis. (This examiner conversed with her in Asante-Twi and was convinced that she was not fluent in the dialect). During the manifestation of GF, however, $\mathrm{HE}$ spoke pure, fluent and impeccable Asante-Twi.

Psychosexual history revealed that HE had met a young man who had returned from Holland on holidays. Denying having any wife or girlfriend, the man promised to marry $\mathrm{HE}$. He introduced $\mathrm{HE}$ to his father but not to the mother, and he would not explain why he avoided the mother. HE introduced him to both parents who accepted him. No sooner had he returned abroad than HE began to get phone calls from Holland, from a lady (call her GF) claiming to be his girlfriend and fiancée. She insulted and threatened $\mathrm{HE}$ and warned her to stay away from him. Two weeks after that HE began to have the experiences recounted, the first of which was at a funeral.

While being interviewed on the first day of our seeing her, HE suddenly stared blank, oblivious and trembled all over the body. She then talked faster than her rate and identified herself as MA saying 'I will never agree; the marriage will be over my dead body. I shall not sit there for her to be taken abroad. I am in league with PM and GF to prevent this marriage.' Asked to call the other two, she said PM would never come but GF would respond. HE then stared again and trembled and another voice, this time in pure Asante-Twi, spoke identifying herself as GF. She confirmed that she was the girlfriend and HE should keep off. When she was done, again blank staring, oblivious and trembling, HE came round without any memory of what had happened.

HE denied any history of sexual abuse in childhood. She claimed she had now taken her mind off the boyfriend following these occurrences. We put her on insight-oriented therapy and antidepressants of $50 \mathrm{mg}$ amitryptiline nocte. She had earlier been put on carbamazepine by a colleague as seizure disorder. On reviewing the diagnosis we tailed off the carbamazepine. The insight oriented therapy consisted of detailed explanation to her of the workings of the mind, unconscious motivation, and giving her literature and vignettes to read on the condition. Within one month the attacks had completely subsided. Electroencephalograph requested, however, came out with changes of temporal lobe epilepsy. We therefore re-introduced carbamazepine. She has been followed up for seven months without any attack. The amitryptiline has been tailed off but the carbamazepine will continue for at least two years till repeat EEG traces normal. Medication will then be tailed off. 


\section{DISCUSSION}

Multiple personality disorder (MPD) is a rare dissociative disorder in which two or more personalities, each complete with its own distinct memories, behaviour and preferences, occur within an individual, with only one of them evident at any time ${ }^{7}$. The distinct personalities are called alters. ${ }^{9}$ The taking over of an alter is sudden and often dramatic, and the personalities may have their separate names and even physiological requirements like one wearing glasses and the other(s) not. Diagnostic and Statistical Manual, fourth edition (DSM-IV) calls the condition Dissociative Identity Disorder. $^{10}$

Early descriptions of MPD included those by Morton Prince ${ }^{11}$ and the examples in The three faces of eve by Thigpen et $\mathrm{al}^{12}$. The condition was considered rare until 1957 since when interest in it has burgeoned and unprecedented number of diagnosis have been made and reported ${ }^{5,9}$. The inclusion of the diagnosis in Diagnostic and Statistical Manual, third edition (DSM-III) sparked off the upsurge of interest. ${ }^{13}$ The literature of the 1980's and 1990's actually shows a proliferation of the condition, largely in North America, ${ }^{14}$ to the extent that in one study in North America researchers were able to interview 102 patients of MPD at four centres ${ }^{15}$. The proliferation has been so much that it has been argued that it can no longer be considered rare ${ }^{15}$. Prevalence as high as 2.4 to $35 \%$ has been quoted for the condition in different psychiatric settings ${ }^{16}$ and $1 \%$ of adult population ${ }^{15}$. Some authors even think it is under-diagnosed ${ }^{17}$ as it may be missed, particularly in children ${ }^{18}$.

But the decade of proliferation was also the decade of skepticism about the condition, with some authors describing the condition as a psychiatric misadventure ${ }^{4}$, others still as iatrogenic or a manufacture $^{5}$. Mai reduced the question to whether practitioners believed in the condition or not. ${ }^{19}$ The author found that $27.8 \%$ of psychiatrists who responded to the questionnaire doubted its existence, and concluded that there is split of opinion about the condition. Merskey even thinks that diagnosing MPD is simply a misdirection of efforts which hinders the resolution of real and serious psychological problems of the patient ${ }^{5}$. Yet another author thinks advocates of MPD are influenced by their own sub-cultural beliefs rather than any objective existence of the condition ${ }^{20}$.

Notwithstanding these criticisms there have been remarkable consistency in the presentation of the condition over time as found by Goff and Simms when they surveyed the literature from 1800 to date. $^{3}$

Authors like Putnam have poignantly defended the diagnosis by arguing that the repeated replication of a core clinical phenomenology demonstrates a construct validity equal to, or superior to, that of accepted codified diagnoses, that both construct and discriminant validity of the diagnosis are supported by the ability of several independently developed diagnostic instruments to blindly discriminate MPD patients from non-dissociative disorder patients with high rates of accuracy, and finally MPD manifests a historical validity absent in most modern era diagnoses ${ }^{21}$. MPD has previously not been reported in Ghana in the knowledge of the present author.

Uncommon as MPD generally is, it is even rarer to have more than two alters. Our second case had four alters. Both patients in our report were women and this follows the known pattern of the disorder being much more common in women ${ }^{3,22}$. It occurs mostly in late adolescence to early adult life. One of our patients was in her twenties conforming to the pattern whereas the other was in her early fifties, an infrequent age group for MPD.

As with all dissociative disorders, the fundamental mechanism underlying MPD is unconscious psychological dissociation - mental elements are dissociated or fragmented. However, unlike other dissociative disorders in which the dissociated mental elements remain fragments of an intact unitary personality, here these elements reunite into well structured, integrated and organised complexities as separate, complete and autonomous functioning personalities as though different individuals occupying the same body at different times. The new personality is often strikingly different from the patient's normal personality; one may be introvert and the other extrovert. The differences may even include physiological changes in one alter not found in another alter, eg EEG changes and temporal perfusion in regional cerebral blood flow changes in one alter which are absent in the other; different reading glasses prescriptions and different intelligence quotients $(\text { IQ's })^{23}$.

The dissociation, as with other dissociative syndromes, serves as a psychological defence mechanism to block out painful conscious awareness of unpleasant mental contents. These disturbing contents might be socially unacceptable fantasies associated with aggressive sexual drives or emotion- 
ally traumatic experiences, like rape and sexual abuse $^{14}$. Rose et al found among 102 patients with MPD that $90.2 \%$ had a history of childhood sexual abuse, $82.4 \%$ had been physically abused in childhood and $95.1 \%$ had had either or both forms of abuse, and $50 \%$ had been abused before age five years $^{15}$. Childhood abuse, physical or sexual, seems a very important common factor in all or most cases of $\mathrm{MPD}^{22}$. One author sees MPD as a defensive altered stated due to autohypnosis which promotes repression and dissociation, and that this, depending on the degree of integration of the ego, results in disturbances of alertness, awareness, memory, and identity. In that article the author presents four vignettes which illustrate a transient hypnoid state. ${ }^{24}$

Some authors have argued that the fact of childhood trauma has been overplayed, ${ }^{4,25}$ though most of these authors, interestingly, are those who do not accept the diagnosis as a valid nosological entity. We did not elicit sexual abuse or childhood physical abuse in any of our patients, but both had events sufficiently worrying and emotionally traumatizing as adults. Miss HE had been deceived by a fiancé who had raised her hopes of being married and taken abroad, assured her he had no other girlfriend, only for his girlfriend to threaten her on the phone. She also had an aunt whom she already perceived as not being favourably disposed towards her, and saw her as being jealous of her relationship. The other, Ms EA, is a second wife and felt insecure in the marriage. Her stepson had the audacity to talk harshly to her on one occasion and asked the father to divorce her, thereby deepening her feelings of insecurity. All these would be traumatic enough to serve as a basis for dissociation in a person who is already suggestible.

The disorder may have an organic basis in the central nervous system. ${ }^{7}$ Furthermore electroencephalpgraphic changes of temporal lobe dysrhythmia in some patients with this condition suggest temporal lobe epilepsy as contributing in some cases. ${ }^{3}$ This is further supported by the fact that there are reports that carbamazepine is useful in some cases. ${ }^{9}$ One of our cases actually had EEG changes of temporal lobe epilepsy and carbamazepine was added to the treatment.

The clinical picture is unmistakable if a patient is seen when an alter is taking over the body, for it is a dramatic phenomenon. The transition is sudden with often the patient staring blank and might, as in our case, tremble. The new alter begins to behave and talk in a very different manner and claim different names. The personalities may have amnesia for one another, though in a few cases one alter may be aware of the other(s). The appearance of an alter may be spontaneous as in our first case or precipitated on demand as in our second case: we could ask one alter to call another alter. This may have been so in this case because the three strange alters were supposedly in league. The differences in the alters may be very remarkable with fundamental physiological differences including optical differences ${ }^{26,27}$.

MPD could be confused with other dissociative disorders like psychogenic fugue and psychogenic amnesia. Those dissociative disorders, unlike MPD, lack a shift in identity. Schizophrenic illness is another differential but formal thought disorder and social deterioration, among other schizophrenic symptoms, will distinguish between them.

These two conditions may also be distinguished using diagnostic tools like Structured Clinical Interview for DSM-IV Dissociative Disorders (SCID) as MPD patients score consistently higher. ${ }^{28}$ An obvious secondary gain should arouse suspicion in malingering. Borderline personality disorders could also behave in a bizarre confusing fashion but the alternating personalities of MPD will be missing. Marmer and Fink have outlined a comparison between these two conditions showing their aetiologic and clinical similarities and differences. ${ }^{29}$ Temporal lobe epilepsy (TLE) is a significant differential. Again the tell-tail alternating personalities in MPD will help to make out the difference. MPD may still have EEG changes of TLE as explained earlier and here we suggest that the predominance of the clinical picture should determine the primary diagnosis.

There are other culturally relevant syndromes to distinguish. The fact that MPD could confuse with possession and trance disorders in the dissociative spectrum is recognized ${ }^{30,31}$. Verbal reports during deliverance in Pentecostal worship indicate that the 'spirit' being exorcised may speak through the 'possessed' body as though an alter. If this lasts only during the deliverance session and does not recur to intrude in the person's secular life, then by definition this is not MPD ${ }^{7}$. It may be a possession state and not a disorder. Ferracuti et al seem to support this view in their study of ten patients who reported of demon-possession and yet maintained normal social functioning ${ }^{32}$. Similarly, personal knowledge of Akan culture shows the pervasive belief that during funerals one may be 'possessed by the spirit of the dead' to direct him in an unfin- 
ished business of the deceased. Again if this does not outlast the funeral and does not interfere with the person's life, this is not MPD. Traditional priests also go through possession states when they seem to have been temporarily taken over by other beings. This author has witnessed these priests in full flight and recognized it as possession state. It is trance state when they seem to have altered consciousness and possession state when consciousness is clear. Both are non-pathological and hence not MPD.

MPD starting early in life tends to have worse prognosis and recovery is generally incomplete. Our second case, however, improved completely with no recurrence in the seven months of followup when earlier she had been having the attacks almost every thirty minutes everyday for one year.

For treatment, extended psychotherapy is recommended as the principal technique, with the aim of merging the alters into a stable single personality. Even so some authors have doubted the costbenefits of such an extended therapy given the fact that psychotherapy may need to be extensive ${ }^{33}$. The alters may be explored in hypnosis or drugassisted interview for traumatic memories and to facilitate cathartic expression and communication between the alters. Antidepressants and anxiolytics may be used as adjuvants to psychotherapy, and anticonvulsants may also help in some cases. Our second patient responded remarkably to psychotherapy, antidepressants and anticonvulsants (carbamazepine) and our psychotherapy did not have to travel beyond two months. We think that for the patient who is capable of understanding, insight therapy offers the patient an understanding of what is happening and enables her to contribute towards her own recovery. Other authors have recommended hypnoplay therapy to help uncover hidden secrets of the patient for a resolution and to help the patient to complete developmentai periods that were curtailed in the psychopathogenesis. ${ }^{34}$

\section{CONCLUSION}

As Putnam shows, the fact that certain core clinical features have been consistently demonstrated in all the cases described over time, among other reasons, is a confirmation of the validity of the disgnosis. Two cases of MPD have been described in this study which are consistent with the typical phenomenology of the condition. Childhood abuse may not always be elicited but some traumatic experience even as adult may be present. Anticonvulsants and antidepressants may be tried in addition to psychotherapy.

\section{REFERENCES}

1. Spanos NP. Multiple identity enactments and multiple personality disorder: a sociocognitive perspective. Psychol Bull Jul 1994; 116(1): 143-165.

2. Beer D, Beer J and Beer J. Multiple personality: self-rape. Psychol Rep Dec 1994; $75(3$ pt1): $1263-1267$.

3. Goff DC, Simms CA. Has multiple personality disorder remained consistent over time? A comparison of past and recent cases. $J$ Nerv Ment Dis Oct 1993; 181(10): 595-600.

4. Seltzer A. Multiple personality: a psychiatric misadventure. Canadian $J$ of Psych - Revue Canadienne de Psychiatrie Sep 1994; 39(7): 442-445.

5. Merskey H. The manufacture of personalities. The production of multiple personality disorder. Br J of Psych Mar 1992; 160: 327-340

6. Dunn GE., Paolo AM, Ryan JJ, Van Fleet JN. Belief in the existence of multiple personality disorder among psychologists and psychiatrist. J of Clin Psychol May 1994; 50(3): 454457.

7. World Health Organization. The ICD-10 Classification of Mental and Behavioural Disorders. Clinical descriptions and diagnostic guidelines. Geneva 1992.

8. Osei AO. Types of psychiatric illness at traditional healing centers in Ghana. Ghana Med $J$ $2001 ; 35(3): 106-110$.

9. Nemiah JC. Disscoiative disorders. In Kaplan HI and Saddock BJ (editors): Comprehensive Textbook of Psychiatry, $6^{\text {th }}$ Ed Baltimore: Williams and Wilkins, US 1995; 1281-1293.

10. American Psychiatric Association: Diagnostic and Statistical Manual of Mental Disorders, Fourth Edition (DSM-IV). Washington DC, American Psych Assoc 1994.

11. Prince M. Dissociation of personality, a biographical study in abnormal psychology. Longmans Green, New York. 1908. 
12. Thigpen $\mathrm{CH}$, Thigpen $\mathrm{H}$, Cleckley HM. The three faces of Eve. McGraw-Hill, New York. 1957

13. Dinwiddie Sh, North CS, Yutzy SH. Multiple personality disorder: scientific and medicolegal issues. Bull of the American Aca of Psych \& the Law 1993; 21(1): 69-79.

14. Ross CA. Epidemiology of multiple personality disorder and dissociation. Psych Clin of North America Sep 1991; 14(3): 503-517.

15. Ross CA., Miller SD, Bjornson L, Reagor P, Fraser GA, Anderson G. Abuse histories in 102 cases of multiple personality disorder. Canadian J of Psych - Revue Canadienne de Psychiatre Mar 1991; 36(2): 97-101.

16. Latz TT, Kramer SI, Hughes DL. Multiple personality disorder among female inpatients in a state hospital. American $J$ of Psych Sep 1995; 152(9): 1343-1348.

17. Kluft RP. Clinical presentations of multiple personality disorder. Psych Clin of North America Sep 1991; 14(3): 605-629.

18. Hornstein NL, Tyson S. Inpatient treatment of children with multiple personality/dissociative disorders and their families. Psych Clin of North America Sep 1991; 14(3): 631-648.

19. Mai FM. Psychiatrists' attitudes to multiple personality disorder: a questionnaire study. Canadian J of Psych-Revue Canadienne de Psychiatrie Apr 1995; 40(3): 154-157.

20. Sarbin TR. On the belief that one may be host to two or more personalities. Intl $J$ of Clin \& Experimental Hypnosis Apr 1995; 43(2): 163183.

21. Putnam FW. Recent research on multiple personality disorder. Psych Clin of North America. Psych Clin of North America Sep 1991; 14(3): 489-502.

22. Murray JB. Dimensions of multiple personality disorder. J of Gen Psych Jun 1994; 155(2): 233-246.

23. Kaplan HI, Saddock BJ. Synopsis of Psychiatry, $6^{\text {th }}$ Ed Baltimore: Williams and Wilkins, US 1991
24. Brenner I. The dissociative character: a reconsideration of "multiple personality". $J$ of the American Psychoanal Assoc 1994; 42(3): 819 846.

25. Piper A Jr. Multiple personality disorder. $\mathrm{Br} J$ of Psych May 1994; 164(5): 600-612.

26. Miller SD, Blackburn T, Scholes G, White GL, Mamalis N. Optical differences in multiple personality disorder. A second look. $J$ Nerv Ment Dis Mar 1991; 179(3): 132-135.

27. Miller S. optical differences in cases of multiple personality disorder. J Nerv Ment Dis 1989; 177: 480-486.

28. Steinbery M, Cicchetti D, Buchanan J, Rakfeldt J, Rounsaville B. Distinguishing between multiple personality disorder (dissociative identity disorder) and schizophrenia using the Structured Clinical Interview for DSM-IV Dissociative Disorders. J Nerv Ment Dis Sep 1994; 182(9): 495-502.

29. Marmer SS, Fink D. Rethinking the comparison of borderline personality disorder and multiple personality disorder. Psych Clin of North America Dec 1994; 17(4): 743-771.

30. Castillo RJ. Spirit possession in South Asia, dissociation or hysteria ? Part 2: Case histories. Cul Med \& Psych Jun 1994; 18(2): 141 162.

31. Richeport MM. The interface between multiple personality, spirit mediumship, and hypnosis. American J of Clin Hypnosis Jan 1992; 34(3): 168-177.

32. Ferracuti S, Sacco R. Dissociative trance disorder: clinical and Rorschach findings in ten persons reporting demon possession and treated by exorcism. J Pers Assess Jun 1996; $66(3): 525$

33. Piper A Jr. Treatment for multiple personality disorder: at what cost? American $J$ of Psychoth Summer 1994; 48(3): 392-400.

34. Shapiro MK. Bandaging a "broken heart": hypnoplay therapy in the treatment of multiple personality disorder. American J of Clin Hypnosis Jul 1991; 34(1): 1-10 